\title{
POLA PERGERAKAN MONYET EKOR PANJANG (Macaca fascicularis) DI CAGAR BUDAYA CIUNG WANARA
}

Pattern Behaviour of Long Tailed Monkeys (Macaca fascicularis)

In Ciung Wanara Cultural Reserve

\author{
Reni Srimulyaningsih $^{1)}$; Lusi Desi Sriwulan Suryadi ${ }^{2)}$ \\ 1) Staf Pengajar di Fakultas Kehutanan Universitas Winaya Mukti, \\ ${ }^{2)}$ Mahasiswa Fakultas Kehutanan Universitas Winaya Mukti \\ Jl Raya Bandung-Sumedang km 29 Tanjungsari, Sumedang 45362
}

\section{Diterima 10 September 2018/Disetujui 1 Oktober 2018}

\begin{abstract}
Ciung Wanara Cultural Reserve (CWCR) is one of famous habitat of Long Tailed Monkeys (LTM). The existence of LTM is one of tourist attraction. But LTM in CWCR became depend on feed by tourists. This condition caused of pattern behaviour of LTM. The objective of this research is to know pattern behaviour of LTM in CWCR. The method of research is councentration count. The result of research is showing of LTM group. There are 4 groups of LTM in CWCR (Pangcalikan, Cikahuripan, Pamangkonan and Patimuan). The LTM pattern behaviour depends on alpha male of group. The pattern sleeping behaviour of LTM group is from the sleeping tree to returns to its sleeping tree. So, there is not overlap of each group, because source of feed, water and cover of LTM is sufficient.
\end{abstract}

Keys words: Pattern behaviour, Long Tail Monkeys, Cultural Reserve

\section{PENDAHULUAN}

Monyet Ekor Panjang atau disingkat menjadi MEP (Macaca fascicularis) merupakan jenis monyet yang memiliki wilayah penyebaran sangat luas, baik di hutan primer maupun hutan sekunder. Populasi MEP secara umum masih dianggap aman sehingga IUCN (International Union for Conservation of Nature 
and Natural Resources) mengkategorikannya dalam status Least Concern, dan oleh CITES (Convention of International Trade Endangered Spesies flora and Fauna) dikategorikan ke dalam Appendix II.

Keberadaan MEP tidak hanya sebagai bagian dari keanekaragaman hayati, namun penting dalam regenerasi hutan tropis, diantaranya adalah sebagai penyemai biji tanaman buah yang penting bagi konservasi jenis tumbuhan. MEP memiliki kemampuan beradaptasi yang sangat tinggi terhadap lingkungan sehingga mampu hidup di berbagai tempat.

Cagar Budaya Ciung Wanara (CBCW) merupakan salah satu wilayah yang terkenal akan keberadaan populasi MEP. CBCW merupakan objek wisata yang berada di Desa Karangkamulyan, Kecamatan Cijeungjing Kabupaten Ciamis dengan luas wilayah 25 hektar. Keberadaan MEP di CBCW merupakan salah satu fauna yang menjadi daya tarik objek wisata pada kawasan tersebut. Banyak pengunjung yang memberi makanan kepada MEP sehingga pergerakan MEP di CBCW tergantung pada keberadaan pengunjung.

Wilayah jelajah MEP sangat ditentukan oleh pergerakanyya mendekati sumber pakan. Pola pergerakan MEP di CBCW cenderung mendekati keberadaan pengunjung, hal ini diduga karena MEP lebih tertarik dengan sumber pakan yang diberikan oleh pengunjung. Pergerakan MEP yang berada di kawasan objek wisata harus memperhatikan pergerakan harianya agar tetap dapat hidup dengan aman dan nyaman di habitatnya. Habitat yang baik seharusnya mampu menyediakan sumber pakan, air dan cover. Hal demikian, perlu dilakukan suatu penelitian mengenai "Pola Pergerakan Monyet Ekor Panjang (Macaca fascicularis) Di Cagar Budaya Ciung Wanara” sebagai salah satu acuan dalam mengetahui pola pergerakan kelompok MEP di lokasi tersebut.

\section{METODE PENELITIAN}

Penelitian ini dilaksanakan pada bulan Agustus 2017. Tempat penelitian dilaksanakan di Cagar Budaya Ciung Wanara, Desa Karangkamulyan Kecamatan Cijeungjing Kabupaten Ciamis (Gambar 1).

Objek yang diteliti adalah pola pergerakan setiap kelompok MEP yang berada di CBCW. Alat yang digunakan pada penelitian ini adalah peta lokasi, GPS (Global Positioning System) untuk menentukan letak dan posisi, Software ArcGIS 10.3 untuk mengolah data, binokuler sebagai alat bantu untuk melihat objek dengan jelas, kamera sebagai alat untuk dokumentasi, pengukur waktu, tally sheet, dan alat tulis. 


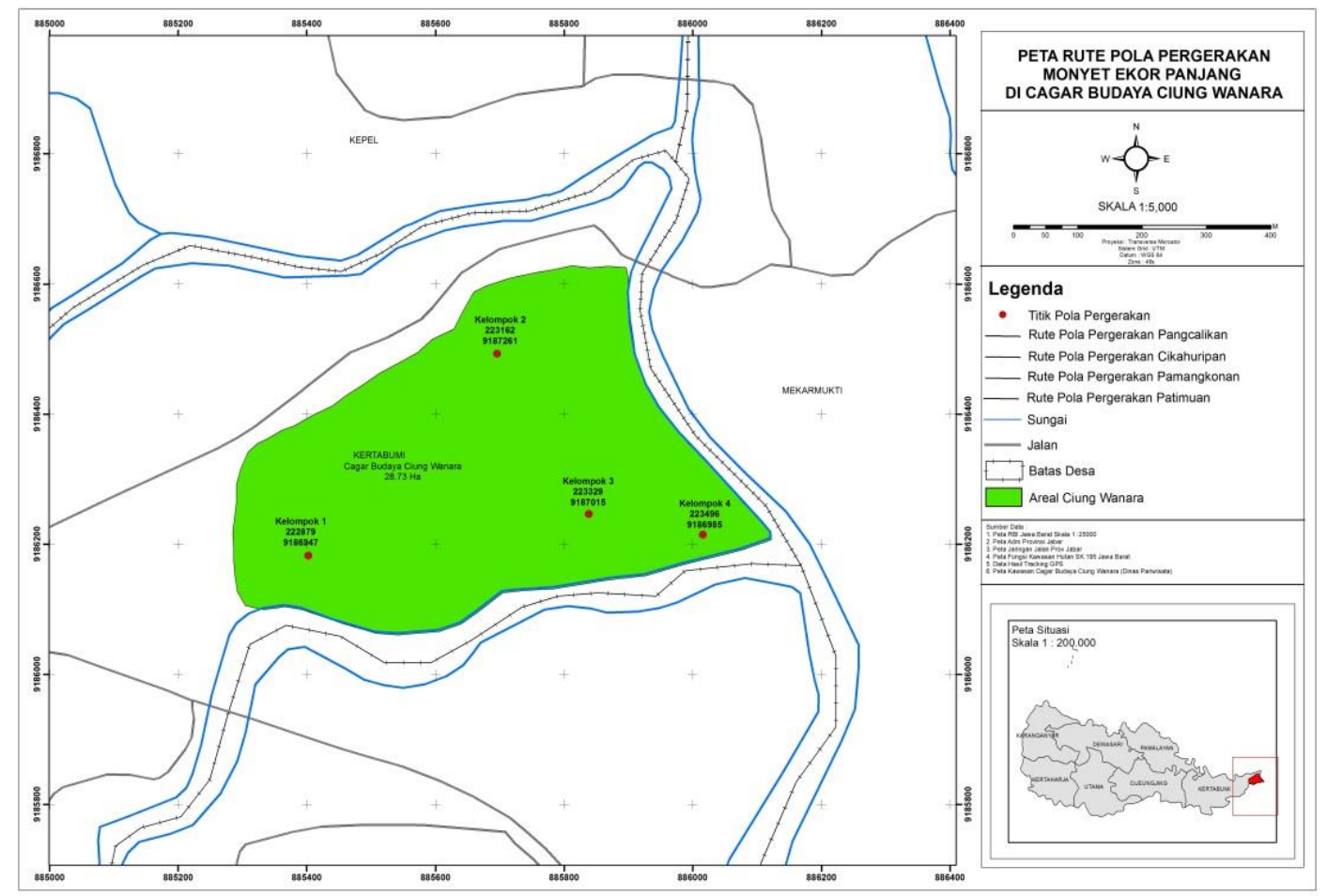

Gambar 1. Peta lokasi penelitian CBCW, kelompok 1: kelompok pangcalikan, kelompok 2: kelompok cikahuripan, kelompok 3: kelompok pamangkonan, dan kelompok 4: kelompok patimuan.

Pengumpulan data menggunakan metode councentration count, yaitu mengikuti pergerakan kelompok MEP dimulai pada pagi hari pada saat kelompok MEP memulai aktivitasnya sehari-hari (jam 06.00 WIB) sampai berhentinya kelompok MEP melakukan aktivitas dan kembali ke pohon tidurnya (jam 17.00 WIB). Kelompok MEP yang diamati dibagi menjadi 4 kelompok, yaitu kelompok Pangcalikan, kelompok Cikahuripan, kelompok Pamangkonan, dan kelompok Patimuan.

Data pola pergerakan MEP di CBCW dianalisis menggunakan software ArcGIS 10.3 dari titik koordinat tempat ditemukannya MEP yang telah dicatat kemudian dimasukkan pada peta lokasi penelitian. Hasil dari pola pergerakan dianalis secara deskriptif. 


\section{HASIL DAN PEMBAHASAN}

\section{Kondisi Habitat Monyet Ekor Panjang (Macaca fascicularis)}

Kondisi habitat MEP di CBCW dilihat dari sumber pakan, air, dan cover (pelindung). Ketiga hal tersebut merupakan komponen penting bagi penunjang kehidupan satwa liar.

\section{A. Sumber Pakan}

Sumber pakan MEP di CBCW terdapat dua sumber, yaitu yang langsung berasal dari alam dan makanan yang diberikan pengunjung. Jenis makanan dari alam yang banyak dikonsumsi MEP di CBCW berupa buah-buahan, tunas dan daun. Jenis pakan tersebut antara lain buah huru (Apodytes combodiana), buah hamperu badak (Tabernaemontana sphaerocarpha), dan tunas daun bambu apus (Gigantochloa apus), sedangkan jenis makanan yang berasal dari pengunjung yang banyak dikonsumsi adalah kacang dan sisa makanan pengunjung.

Hal ini berbeda dengan MEP di Hutan Rakyat Ambender, Pamekasan, Madura (Zairina et all. 2015) terdapat 22 jenis tumbuhan hutan yang dijadikan sebagai pakan MEP baik berupa buah, bunga dan daun, diantaranya duwek (Syzygium cumini), nyato (Palaquium eriocalyx), kalak (Uvaria purpurea), polai (Alstonia scholaris), kendal (Cordia gantamensis), dan sanek (Copparis acuminata). Jenis pakan MEP ini juga berbeda dengan pakan yang berada di Hutan Pendidikan Gunung Walat yang memanfaatkan 7 jenis pakan (Santosa et all. 2013), yaitu pinus (Pinus merkusii), puspa (Schima wallici), kayu afrika (Maesopsis eminii), harendong (Bellucia axinanthera), agatis (Aganthis lorantifolia), teureup (Arthocarpus elastica) dan tepus (Amomum coccineum). Perbedaan jenis pakan ini diperkirakan adanya perbedaan habitat pada masingmasing tempat, namun pada dasarnya komposisi pakannya lebih banyak buahbuahan dan pakan tambahannya berupa pucuk, daun, umbi dan biji-bijian. Seperti halnya

\section{B. Sumber Air}

Kebutuhan satwa liar untuk keberlangsungan hidupnya selain pakan, juga memerlukan air. Alikodra (2002) menyatakan bahwa satwa liar memerlukan air untuk berbagai proses, yaitu pencernaan makanan dan metabolisme, mengangkut bahan-bahan sisa, dan untuk pendinginan dalam proses evaporasi. Dari segi ketergantungan terhadap air, MEP termasuk satwa yang hidupnya kurang 
tergantung pada air. Air bagi MEP hanya untuk memenuhi minum dan tidak ada kebutuhan air untuk berkubang atau berendam.

Sumber air yang terdapat di CBCW adalah Sungai Cimuntur dan Sungai Citanduy. Apabila musim penghujan turun maka sungai akan penuh dengan air, namun pada musim kemarau tiba aliran sungai sedikit surut. Pada saat pengamatan dilakukan, musim yang sedang terjadi adalah musim kemarau sehingga aliran sungai sedikit surut.

Kelompok MEP yang berada dekat dengan sumber air adalah MEP kelompok Pamangkonan dan MEP kelompok Patimuan. Berdasarkan informasi dari pihak pengelola, MEP memanfaatkan sumber air tersebut untuk minum. Namun selama pengamatan dilakukan tidak terlihat kedua kelompok MEP memanfaatkan sumber air tersebut. MEP yang berada di CBCW dalam memenuhi kebutuhan air melalui embun pada daun dan buah-buahan. Meski demikian kebutuhan air bagi MEP di CBCW tetap dapat terpenuhi karena MEP tidak membutuhkan banyak air untuk minum.

\section{Jenis Cover (Pelindung)}

Cover atau pelindung pada satwa merupakan suatu tempat dapat berupa hamparan vegetasi, atau pohon yang sering digunakan satwaliar sebagai tempat berlindung dari ancaman dan untuk berkembang biak. Cover bisa dikatakan juga sebagai suatu struktur lingkungan yang melindungi kegiatan reproduksi dari berbagai kegiatan-kegiatan satwaliar. Salah satu komponen struktur yang berperan sebagai pelindung adalah vegetasi.

Cover sangat diperlukan untuk menjamin berlangsungnya berbagai aktivitas dan untuk mempertahankan kehidupannya, sehingga perannya sangat penting bagi kehidupan MEP. Seperti jenis primata lainnya, jenis pohon yang digunakan MEP sebagai cover (pelindung) adalah pohon yang dekat atau menjadi sumber pakannya. Berdasarkan hasil pengamatan, pohon yang sering digunakan MEP antara lain pohon dahu (Dracontomelon mangiferum), pohon kadoya (Disoxylum amooraides), pohon nyatoh (Payena acuminata), pohon kihideung (Dyospyros evena), pohon kisapi (Aporosa arborea), pohon bungur (Langerstromia ovalivolia), kemuning (Murraya paniculata), pohon angsana (Pterocarpus indicus), dan pohon jati putih (Gmelina arborea).

Menurut Baihaqi et all (2017), pohon yang dipilih MEP untuk tidur mempunyai karakter antara lain mempunyai tinggi antara 16 hingga $20 \mathrm{~m}$, berdiameter batang 20 sampai $40 \mathrm{~cm}$. Karakter ini dipilih agar kelompok MEP yang berada di pohon tersebut dapat mudah memandang dan mengetahui keadaan 
(ancaman predator atau persaingan jika ada kelompok MEP lainnya) di sekitarnya.Pohon yang digunakan sebagai pohon tidur kelompok MEP antara lain adalah pohon dahu (Dracontomelon mangiferum), pohon kadoya (Disoxylum amooraides), pohon kimaung (Bischoffia javanica), pohon bungur (Langerstromia ovalivolia), pohon kihideung (Dyospyros evena) dan pohon kisapi (Aporosa arborea).

\section{Pola Pergerakan Monyet Ekor Panjang (Macaca fascicularis)}

Pergerakan MEP di CBCW selalu berkelompok dengan dipimpin oleh jantan dewasa yang dominan atau pemimpin kelompoknya. Pergerakan MEP dilakukan dengan cara berjalan, berlari ataupun berlompat lompatan dari cabang ke cabang, sehingga jenis pergerakan MEP dapat diklasifikasikan ke dalam quadropedalism dengan katagori berjalan dengan menggunakan empat anggota badannya, selain itu juga dikatakan sebagai vertical clinging and leaping yaitu bisa meloncat dan memanjat.

Menurut Alikodra (2002), jika secara sepintas kita mengamati kehidupan satwa liar di habitat alamnya, akan diperoleh kesan bahwa mereka bergerak dari satu tempat ke tempat yang lainnya tanpa aturan. Akan tetapi jika diperhatikan secara teliti akan terlihat bahwa mereka melakukan pergerakan secara teratur secara berkala. Hal ini dilakukan juga oleh kelompok MEP di CBCW. Pergerakan masing-masing kelompok MEP di CBCW akan dijelaskan sebagai berikut:

\section{A. Kelompok Pangcalikan}

Jumlah MEP kelompok Pangcalikan yang ditemukan pada saat pengamatan adalah 48 individu. Dalam melakukan pergerakannya, MEP kelompok Pangcalikan memulai aktivitasnya dalam mencari makan dimulai dari pukul 06.00 WIB sampai dengan pukul 17.00 WIB. Wilayah jelajah MEP kelompok Pangcalikan adalah seluas 2,08 hektar. Sebelum melakukan aktivitasnya MEP kelompok Pancalikan akan berjemur di pohon-pohon yang tinggi terlebih dahulu untuk memanaskan tubuh mereka. Pada pagi hari sekitar pukul 06.00 WIB sampai pukul 08.00 WIB, MEP kelompok Pancalikan masih berada di sekitar pohon tidurnya. Pohon yang dijadikan pohon tidur oleh MEP kelompok Pangcalikan adalah pohon kadoya (Dysoxylum amooroides) dan pohon dahu (Dracontomelon mangiferum).

Sekitar pukul 08.00 WIB sampai dengan pukul 09.00 WIB, MEP kelompok Pangcalikan bergerak ke sekitar area Situs Pangcalikan. Pada lokasi ini kelompok MEP banyak melakukan aktivitas makan dan bermain. Di lokasi ini terdapat 
vegetasi bambu apus (Gigantochloa apus), sehingga di lokasi ini MEP melakukan aktivitas makan karena tunas daun bambu apus merupakan salah satu jenis pakan yang dikonsumsi oleh MEP. Beberapa pohon sering pula digunakan sebagai tempat bermain memanjat dan bergelantungan seperti pohon kemuning (Murraya paniculata), pohon angsana (Pterocarpus indicus), dan pohon jati putih (Gmelina arborea).

Sekitar pukul 09.00 WIB sampai sekitar pukul 13.00 WIB MEP kelompok Pangcalikan berada di sekitar pintu masuk, area parkir, kios pedagang dan area pembuangan sampah. Pada lokasi sekitar pintu masuk dan area parkir, MEP sering diberi makanan oleh pengunjung sehingga MEP kelompok Pangcalikan akan tetap berada di sekitar area parkir dan kios pedagang untuk melakukan aktivitas hariannya. Sedangkan pada area pembuangan sampah, kelompok MEP Pangcalikan mengacak-acak tumpukan sampah dan memakan sisa makanan yang berada di pembuangan sampah tersebut. Hal ini terjadi karena kelompok MEP tersebut terbiasa memakan makanan non alami (makanan dari pengunjung) dibanding makanan alaminya.

Sekitar pukul 13.00 WIB sampai dengan pukul 17.00 WIB, MEP kelompok Pangcalikan berpindah ke area tempat bermain anak. Di lokasi ini kelompok MEP beristirahat dan melakukan aktivitas menelisik (grooming). Pohon yang digunakan MEP untuk beristirahat adalah pohon dahu (Dracontomelon mangiferum). Vegetasi di lokasi ini antara lain bambu apus (Gigantochloa apus), kanari monyet (Canaricum denticulatum), kihideung (Dyospyros evena), dahu (Dracontomelon mangiferum), dan katapang (Terminalia catappa). Setelah pukul 17.00 WIB kelompok MEP biasanya mulai bergerak pulang kembali ke pohon tidurnya untuk melakukan aktivitas istirahat/tidur.

Pergerakan kelompok MEP Pangcalikan meliputi beberapa area dimulai dari pohon tidur, kemudian bergerak menuju sekitar area Situs Pangcalikan, kemudian bergerak kembali ke sekitar pintu masuk, area parkir, kios pedagang, area pembuangan sampah, dan pada siang hari kelompok MEP Pangcalikan bergerak ke sekitar area tempat bermain anak untuk beristirahat dan pada sore hari MEP kelompok Pangcalikan kembali ke pohon tidurnya (Gambar 2).

\section{B. Kelompok Cikahuripan}

Jumlah MEP kelompok Cikahuripan yang ditemukan pada saat pengamatan adalah 17 individu. Dalam melakukan pergerakannya, MEP kelompok Cikahuripan memulai aktivitasnya dalam mencari makan dimulai dari 
pukul 06.00 WIB sampai dengan pukul 17.00 WIB. Wilayah jelajah MEP kelompok Cikahuripan adalah seluas 1,43 hektar.

Pohon yang dijadikan pohon tidur oleh MEP kelompok Cikahuripan adalah pohon kimaung (Bischoffia javanica) dan pohon dahu (Dracontomelon mangiferum). Pada pukul 06.00 WIB sampai dengan pukul 08.00 WIB, MEP kelompok Cikahuripan masih berada di sekitar pohon tidurnya.

Sekitar pukul 08.00 WIB sampai dengan pukul 10.00 WIB, MEP kelompok Cikahuripan kemudian bergerak ke sekitar area Situs Lambang Peribadatan. Pada lokasi ini kelompok MEP banyak melakukan aktivitas bermain dan melakukan aktivitas lain seperti kawin dan menelisik (grooming). Vegetasi lokasi ini antara lain bambu apus (Gigantochloa apus), bungur (Langerstromia ovalivolia), nyatoh (Payena acuminata), dan kadoya (Dysoxylum amooroides).

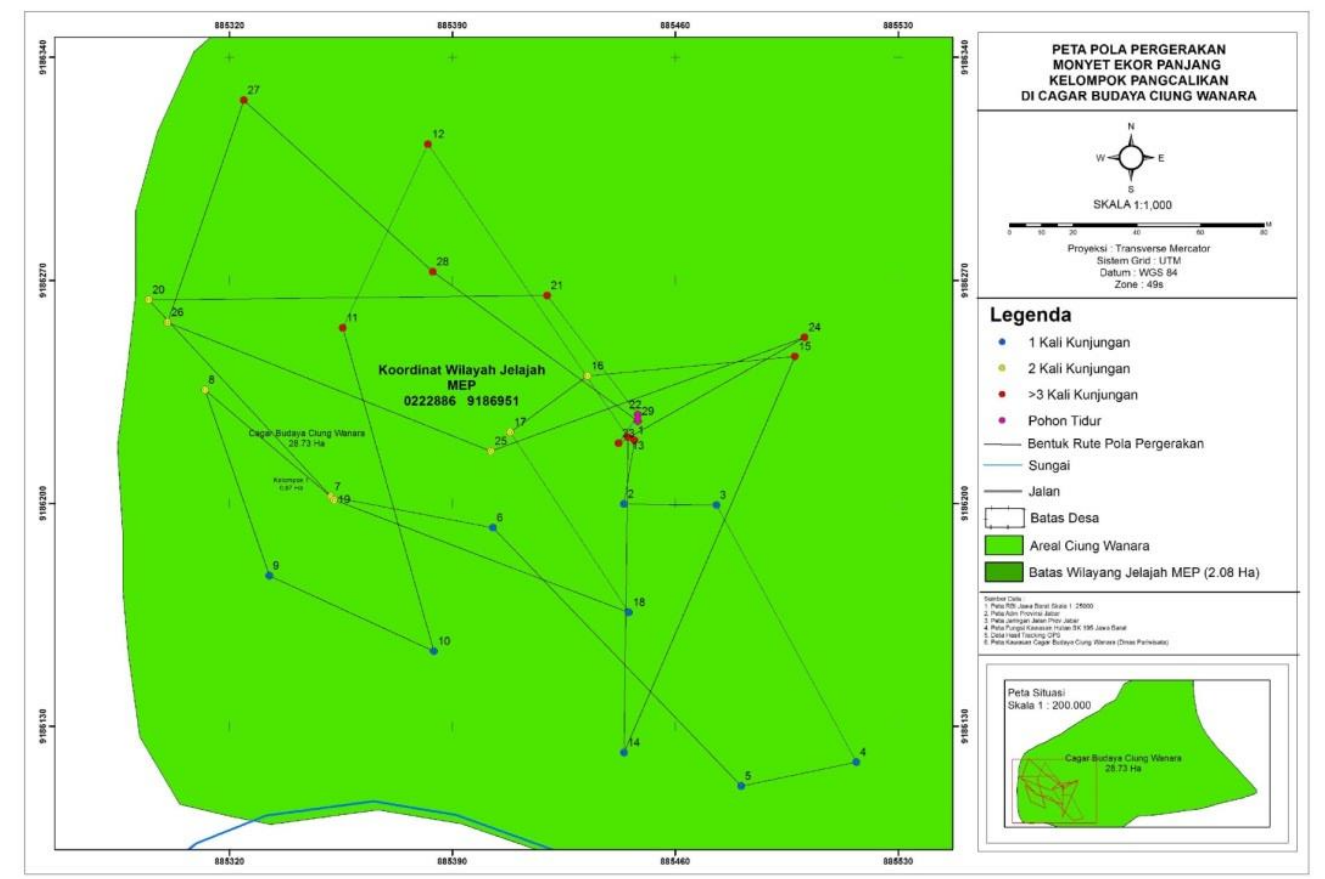

Gambar 2. Pola pergerakan harian MEP kelompok Pangcalikan

Sekitar pukul 10.00 WIB sampai dengan pukul 12.00 WIB, MEP kelompok Cikahuripan bergerak ke area Situs Cikahuripan. Di lokasi ini, kelompok MEP Cikahuripan lebih banyak melakukan aktivitas bermain dan makan. Selain itu juga, di lokasi ini MEP kelompok Cikahuripan sering berinteraksi dengan pengunjung. Dimana pengunjung memberi makan kepada MEP tersebut, karena setiap pengunjung yang datang kebanyakan membawa makanan untuk MEP. Sehingga MEP kelompok Cikahuripan lebih lama berada di sekitar Situs 
Cikahuripan, untuk mendapatkan makanan dari pengunjung. Apabila di area ini tidak dijumpai pengunjung, terkadang MEP kelompok Cikahuripan bergerak keluar kawasan CBCW.

Sekitar pukul 12.00 WIB sampai dengan pukul 14.00 WIB, MEP kelompok Cikahuripan kemudian bergerak ke sekitar Situs Sang Hyang Bedil. Di lokasi ini MEP kelompok Cikahuripan beristirahat di pohon dahu (Dracontomelon mangiferum) dan bungur (Langerstromia ovalivolia). Menurut Sulistyadi et all (2013), bahwa pada siang hari MEP lebih banyak bergerak dan beristirahat. Aktivitas bergerak sangat terkait dengan upaya mencari sumber pakan serta kegiatan orientasi daerah jelajah, sedangkan aktivitas istirahat dilakukan sebagai bentuk efisiensi energi dan upaya menghindari panas matahari yang berlebihan.

Sekitar pukul 14.00 WIB sampai dengan pukul 17.00 WIB, MEP kelompok Cikahuripan kembali ke sekitar area Situs Cikahuripan. Pada lokasi ini kelompok MEP terlihat kembali melakukan aktivitas makan dan melakukan aktivitas lainnya seperti bermain, menelisik (grooming), kawin, dan bergelantungan. Setelah pukul 17.00 WIB kelompok MEP mulai bergerak pulang kembali ke pohon tidurnya untuk melakukan aktivitas istirahat/tidur.

Dapat diketahui bahwa pergerakan MEP kelompok Cikahuripan meliputi beberapa area dimulai dari pohon tidur, kemudian bergerak menuju sekitar area Situs Lambang Peribadatan, kemudian bergerak ke sekitar Situs Cikahuripan, kemudian bergerak ke sekitar Situs Sang Hyang Bedil, kemudian bergerak kembali ke sekitar Situs Cikahuripan, dan pada sore hari MEP kelompok Cikahuripan kembali ke pohon tidurnya. Adapun pola pergerakan harian MEP kelompok Cikahuripan dapat dilihat pada Gambar 3.

\section{Kelompok Pamangkonan}

Jumlah MEP kelompok Pamangkonan yang ditemukan pada saat pengamatan adalah 8 individu. Dalam melakukan pergerakannya, MEP kelompok Pamangkonan memulai aktivitasnya dalam mencari makan dimulai dari pukul 06.00 WIB sampai dengan pukul 17.00 WIB. Wilayah jelajah MEP kelompok Pamangkonan adalah seluas 0,62 hektar.

Pohon yang dijadikan pohon tidur oleh MEP kelompok Pamangkonan adalah pohon kihideung (Dyospyros evena). Pada pukul 06.00 WIB sampai dengan pukul 09.00 WIB, MEP kelompok Pamangkonan masih berada di sekitar pohon tidurnya. Aktivitas yang dilakukan berupa makan, menelisik (grooming), bergelantungan dan kawin. 


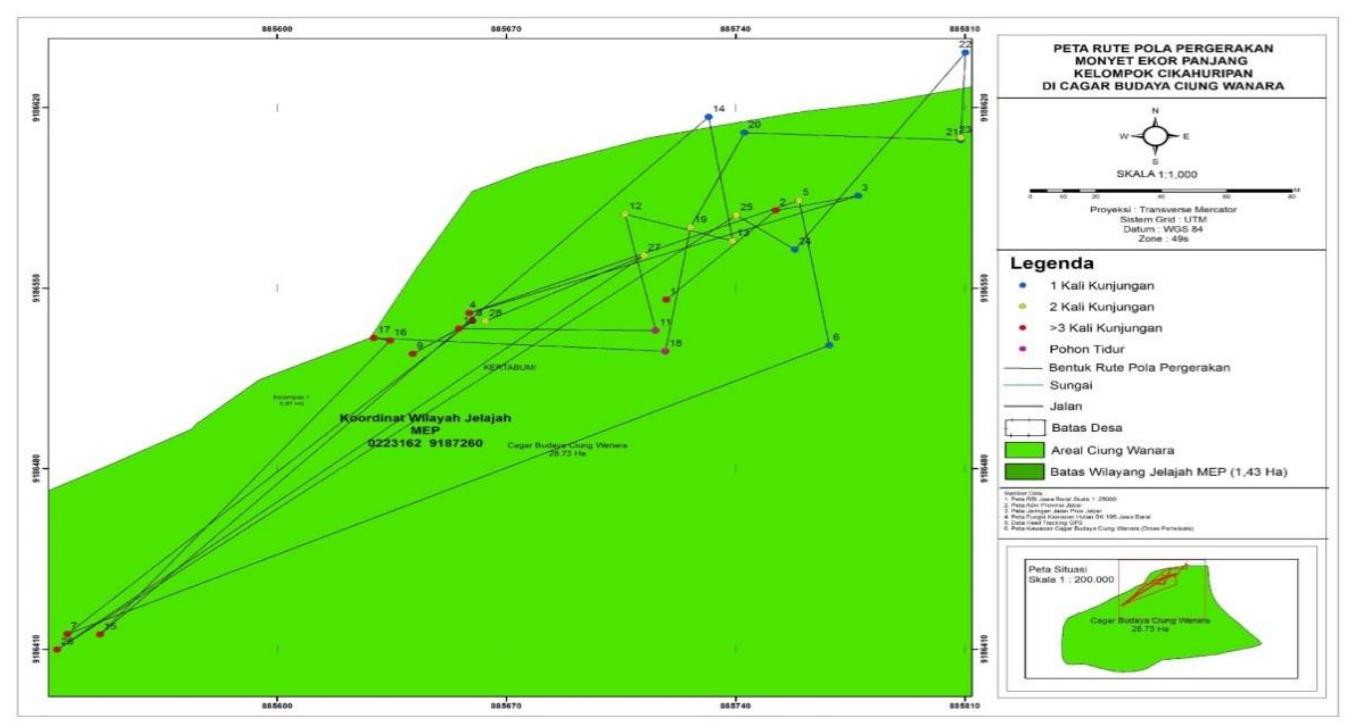

Gambar 3. Pola pergerakan harian MEP kelompok Cikahuripan

Sekitar pukul 09.00 WIB sampai dengan pukul 11.00 WIB, MEP kelompok Pamangkonan bergerak ke area Situs Makam Adipati Panaekan. Di lokasi ini, MEP kelompok Pamangkonan melakukan aktivitas bermain. Beberapa pohon sering pula digunakan sebagai tempat bermain memanjat dan bergelantungan seperti pohon angsana (Pterocarpus indicus), mahoni (Sweitenia mahagoni) dan pohon nyatoh (Payena acuminata).

Sekitar pukul 11.00 WIB sampai dengan pukul 14.00 WIB, MEP kelompok Pamangkonan bergerak ke dalam hutan. Pada lokasi ini kelompok MEP beristirahat di pohon dahu (Dracontomelon mangiferum), selain beristirahat terlihat juga aktivitas lainnya seperti kawin, menelisik (grooming), dan makan.

Sekitar pukul 14.00 WIB sampai dengan pukul 17.00 WIB, MEP kelompok Pamangkonan bergerak ke area Situs Pamangkonan. Di lokasi ini MEP kelompok Pamangkonan banyak melakukan aktivitas makan dan bermain. Setelah pukul 17.00 WIB kelompok MEP mulai bergerak pulang kembali ke pohon tidurnya untuk melakukan aktivitas istirahat/tidur.

Dapat diketahui bahwa pergerakan MEP kelompok Pamangkonan meliputi beberapa area dimulai dari pohon tidur, kemudian bergerak ke sekitar area Situs Makam Adipati Panaekan, kemudian bergerak ke dalam hutan, kemudian bergerak ke area Situs Pamangkonan dan pada sore hari MEP kelompok Pamangkonan kembali ke pohon tidurnya. Adapun pola pergerakan harian MEP kelompok Cikahuripan dapat dilihat pada Gambar 4. 


\section{Kelompok Patimuan}

Jumlah MEP kelompok Patimuan yang ditemukan pada saat pengamatan adalah 11 individu. Dalam melakukan pergerakannya, MEP kelompok Patimuan memulai aktivitasnya dalam mencari makan dimulai dari pukul 06.00 WIB sampai dengan pukul 17.00 WIB. Wilayah jelajah MEP kelompok Patimuan adalah seluas 0,7 hektar. Pohon yang dijadikan pohon tidur oleh MEP kelompok Patimuan adalah pohon kadoya (Dysoxylum amooroides). Pada pukul 06.00 WIB sampai dengan pukul 09.00 WIB, MEP kelompok Patimuan masih berada di sekitar pohon tidurnya.

Sekitar pukul 09.00 WIB sampai dengan pukul 12.00 WIB, MEP kelompok Patimuan kemudian bergerak ke sekitar area Situs Patimuan. Pada lokasi ini kelompok MEP banyak melakukan aktivitas bermain dan makan. Selain itu juga, di lokasi ini MEP kelompok Cikahuripan sering berinteraksi dengan pengunjung. Sekitar pukul 12.00 WIB sampai dengan pukul 14.00 WIB, MEP kelompok Patimuan bergerak ke dalam hutan. Pada lokasi ini kelompok MEP beristirahat di pohon kisapi (Aporosa arborea).

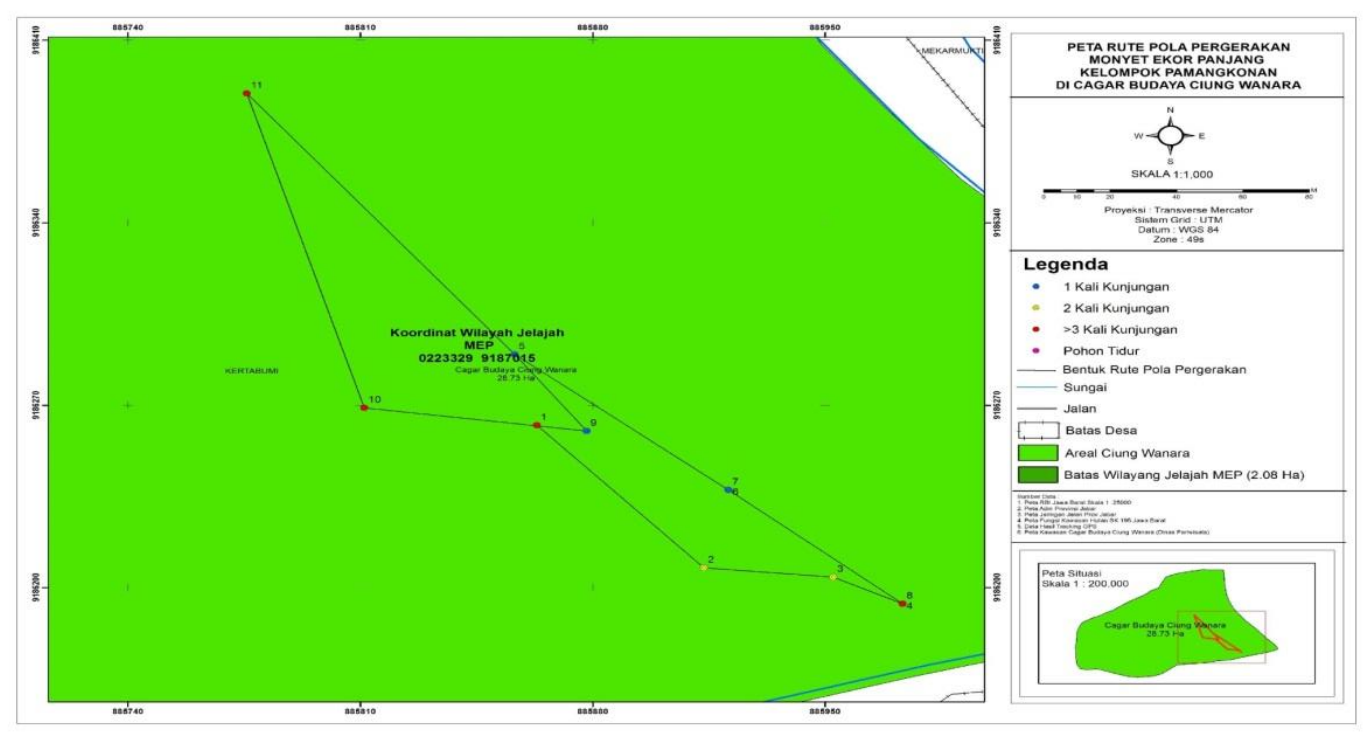

Gambar 4. Pola pergerakan harian MEP kelompok Cikahuripan

Setelah berisirahat, MEP kelompok Patimuan kembali melakukan pergerakan. Di lokasi ini MEP banyak melakukan aktivitas makan, karena lokasi ini di dominasi oleh bambu yang menjadi tempat aktivitas makan kelompok MEP tersebut. Menurut Rahayu (2007), tunas daun bambu merupakan salah satu pakan MEP. Sehingga pada lokasi ini dijadikan tempat untuk beraktivitas makan. Selain 
beraktivitas makan, pada daerah ini kelompok MEP melakukan aktivitas lainnya seperti menelisik (grooming) dan kawin. Setelah pukul 17.00 WIB kelompok MEP mulai bergerak pulang kembali ke pohon tidurnya untuk melakukan aktivitas istirahat/tidur.

Dapat diketahui bahwa pergerakan MEP kelompok Cikahuripan meliputi beberapa area dimulai dari pohon tidur, kemudian bergerak menuju sekitar area Situs Patimuan, kemudian bergerak ke dalam hutan, dan pada sore hari MEP kelompok Cikahuripan kembali ke pohon tidurnya. Adapun pola pergerakan harian MEP kelompok Patimuan dapat dilihat pada Gambar 5.

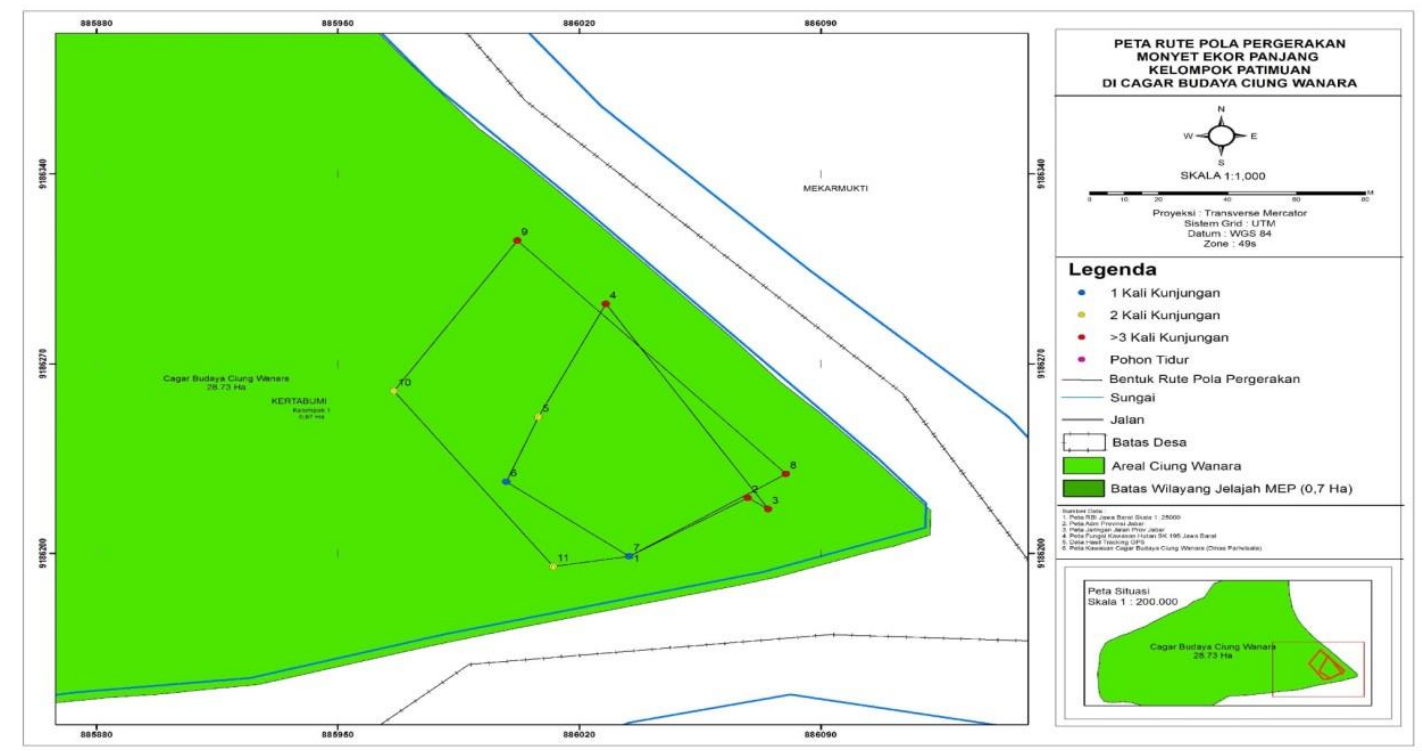

Gambar 5. Pola pergerakan harian MEP kelompok Patimuan

\section{Tumpang Tindih Tempat}

Pergerakan kelompok MEP di CBCW memiliki pergerakan kelompoknya masing-masing dan memiliki tempat yang digunakan untuk beraktivitasnya sehari-hari, seperti mencari makan, bermain, pohon tidur, dan aktivitas lainnya. Sehingga tidak terjadinya tumpang tindih tempat antara kedua kelompok tersebut dalam melakukan aktivitas hariannya. Hal ini karena sumber pakan, air dan cover MEP di kawasan ini tercukupi, sehingga tidak mengganggu kawasan MEP kelompok lain.

Pergerakan MEP di CBCW dalam wilayah jelajahnya selain ditentukan oleh sumber pakan juga dipengaruhi oleh adanya aktivitas manusia. Kelompok Pangcalikan, kelompok Cikahuripan dan kelompok Patimuan cenderung lebih memilih untuk menunggu pemberian makanan dari pengunjung dibandingkan 
dengan mencari sumber pakan alami ke dalam hutan, sedangkan kelompok Pamangkonan mencari sumber pakan ke dalam hutan. Adapun pola pergerakan kelompok MEP di CBCW disajikan pada peta (Gambar 6).

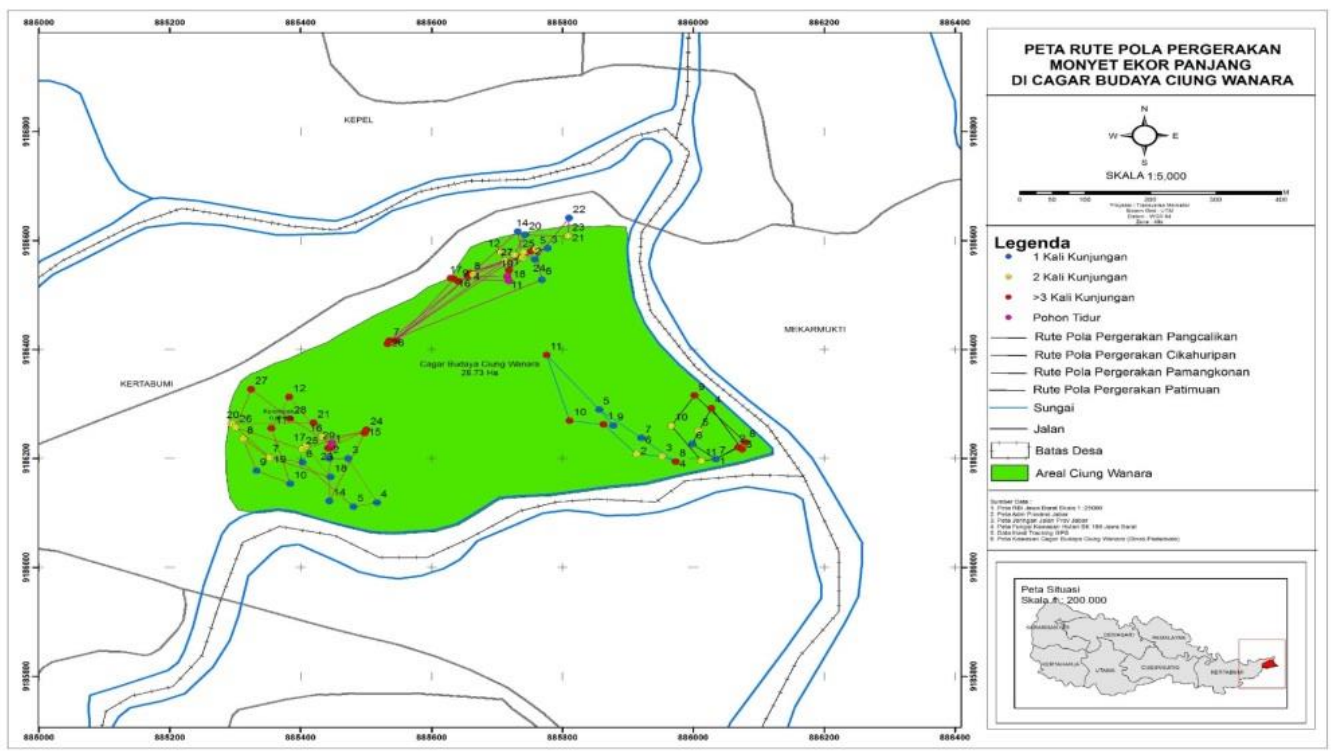

Gambar 6. Pola pergerakan kelompok MEP di CBCW

\section{KESIMPULAN}

Kelompok MEP yang berada di CBCW terdapat empat kelompok. Pergerakan MEP di kawasan ini teratur dengan mengikuti arah pergerakan dari pemimpin kelompoknya. Jenis pergerakan MEP dapat diklasifikasikan ke dalam quadropedalism, selain itu juga dikatakan sebagai vertical clinging and leaping. Arah pergerakan MEP dimulai dari pohon tidur sampai kembali lagi ke pohon tidurnya. Kelompok MEP yang berada di $\mathrm{CBCW}$ memiliki pergerakan kelompoknya masing-masing. Sehingga tidak terjadi tumpang tindih tempat antar keempat kelompok tersebut, hal ini dikarenakan sumber pakan, air dan cover MEP di kawasan ini tercukupi.

\section{DAFTAR PUSTAKA}

Alikodra HS. 2002. Pengelolaan Satwa Liar Jilid I. Yayasan Penerbit Fakultas Kehutanan Institut Pertanian Bogor. Bogor.

Baihaqi A, Setia TM, Sugardjito J, Lorenzo G. 2007. Penggunaan Pohon Tidur Monyet Ekor Panjang (Macaca fascicularis) Di Hutan Lindung Angke 
Kapuk Dan Ekowisata Mangrove Pantai Indah Kapuk Jakarta. Universitas Nasional. Jakarta.

Santosa Y, A Hidayat, AH Mustari. 2013. Studi Populasi dan Pola Penggunaan Ruang Monyet Ekor Panjang (Macaca fascicularis) di Hutan Pendidikan Gunung Walat. Media Konservasi 18 (1) : 40-46. Bogor. DKSHE IPB.

Zairina A, B Yanuwiadi, S Indriyani. 2015. Pola Penyebaran harian dan Karakteristik Tumbuhan Pakan Monyet Ekor Panjang (Macaca fascicularis R.) di Hutan Rakyat Ambender, Pamekasan, Madura. J-PAL 6(1) : 1-12. Malang. Universitas Brawijaya. 